Prof. Gough described the vascular changes in the lungs in this disease and also indicated the value of studying the grosser pathology of the lungs with the aid of paper-mounted sections. Prof. P. R. Allison (Oxford) described his technique of studying left atrial pressures by puncture of the atrium with a needle inserted down a bronchoscope. His objective was an attempt to distinguish, on the basis of the pressure tracings he obtained, between cases of mitral stenosis and mitral incompetence. The results showed a sharp separation between the two groups, but this clear-cut result (as became apparent in the later discussion) may have been in part due to the selection of patients for a surgical opinion. The view was expressed by Dr. P. Wood (Institute of Cardiology, London) that the results might well have been less clear if an unselected series of cases of disease of the mitral valve was studied. Prof. A. C. Lendrum (Queen's College, Dundee) described his studies on the histology of the small arteries of the lungs in mitral stenosis. The deposition of fibrin in the vessel walls and the distortion of neighbouring nuclei resemble the changes seen in other diseases affecting different organs of the body. He attributed these changes in the lungs to a raised pressure in the pulmonary artery and illustrated them with most pleasing colour photomicrographs.

The discussion of all these papers delivered on the first day of the symposium did not serve to increase our knowledge of the mechanisms involved in the many and complicated effects discussed by the principal speakers, except, perhaps, the contribution of Dr. G. de J. Lee (St. Thomas's Hospital, London), who stated that appropriate measurements made during a Valsalva manœuvre indicate the existence of vasomotor phenomena in the lungs.

On the second day of the symposium, Dr. G. S. Dawes (Nuffield Institute, Oxford) described his experiments on the pulmonary function of new-born lambs, and the changes which take place during the first fow hours of life. His observations show the importance of arterio-venous anastomoses (for example, patent ductus arteriosus) in the new-born lamb, which have the effect of tiding it over the period during which its lungs are becoming more distensible and more fully aerated. He emphasized the need for caution in applying his results to babies as we do not as yet know enough about the details of the circulation in the baby immediately after birth. Prof. W. Melville Arnott (Department of Medicine, Birmingham) described a selection of the numerous tests of lung function now available, and assessed their value as aids to diagnosis. Dr. D. V. Bates (St. Bartholomew's Hospital, London) reported on his experiments on gas diffusion studies as an aid to the assessment of lung function. $\mathrm{He}$ concluded that impaired alveolo-capillary diffusion is probably best revoaled by a study of the 'diffusing capacity' of nitrous oxide. It is difficult to feel convineed about this, because one would imagine that diffusing capacity and ventilation of the alveoli are in some degree interdependent, and his method of calculating the diffusing capacity certainly does not take into account any ventilatory factor. Dr. L. G. C. E. Pugh (London) deseribed the numerous devices (volumecycled and pressure-cycled) now used for maintaining artificial ventilation for long periods. This com. munication had much topical interest in view of the present rise in incidence of poliomyelitis. Prof. I. Donald (Department of Midwifery, Glasgow) described a patient-cycled respirator which he has used successfully for assisted respiration in new-born babies. His physiological observations seomed to support some of those described by Dr. Dawes.

The discussion on the papers delivered on the second day of the symposium was noteworthy for two reasons. On one hand, it was clear that workers, conscious of the difficulty of human experimentation, were anxious to discover more about the physiological basis of the various tests of pulmonary function. On the other hand, a noteworthy contribution by Dr. R. Coope (Liverpool) reminded one that, in general, the tests of function which had been discussed had, as yet, only a limited application as aids to diagnosis. The symposium was a success both on the academic and the social sides. Queen's College went to great lengths to make the stay enjoyable, and it is no exaggeration to say that all the members of the symposium returned home refreshed in mind and body.

J. L. D'Strva

\section{READING TECHNICAL COLLEGE}

T M THE QUEEN MOTHER opened the 1. V1. new Technical College of the County Borough of Reading on October 26. This College was first foreshadowed by various Science and Art classes (under the South Kensington regulations); and these classes, which were already being maintained in $\mathbf{1 8 8 2}$ by the local authority of Reading, themselves arose on foundations laid earlier by various individuals of vision and vigour. By 1892 a new University Extension College, associated with Christ Church, Oxford, had come into being in Reading and had incorporated the former Science and Art classes.

Eventually, the University College received its charter - to become the University of Reading of to-day-but additional evening classes for local students were continued without break for more than fifty years. Thus, by tradition-and no less by the close co-operation of to-day-important and enduring links have been forged between gown and town. During that same half-century, classes for younger students were also being developed at junior evening institutes by the local authority at Reading.

In 1946 the local authority--having already decided to provide a new technical college, and having acquired a building site-recovered from the University full responsibility for evening courses in engineering, building and commerce; and after a transitional session, the new Technical College organization came into being in September 1947. Its first task was to co-ordinate the existing senior and junior evening classes and to provide for their unified direction in the future. The University continued to provide accommodation (and is still so doing), but demand grew rapidly and the local authority found supplementary accommodation at some thirty additional places-thanks in particular to assistance from industry, schools, the Royal Berkshire Hospital, the public libraries, and various undertakings.

The second objective was the development of a service no longer restricted only to evening-work. Lack of accommodation for day-work was a serious difficulty.

The range of local need wais wide. Reading is characterized not by any one predominating industry but by a wide spread of interest. Needs were also urgent, and the authority adopted a bold policy in an endeavour to meet them by compromise, adaptation and by co-operation willingly given on all sides. 
Meanwhile, adequate new premises were planned in consultation with the appointed architects, Messrs. Lanchester and Lodge, of London. Work on the site began on October 2, 1950 ; the foundation stone was laid by the chairman of the Board of Governors (who at that time was also mayor of Reading) on October 3, 1952 .

Transfer of the widely dispersed work of the College to the new buildings began at Easter 1955, when the top floor of the main block was handed over, and continued throughout the summer. This operation was completed early in September.

The College is at present organized in six departments : art and printing; building; commerce; domestic and women's trades subjects; engineering; science. During the first three weeks of the present session, 3,400 students enrolled and commenced their year's work : 1,700 for full-time and part-time day courses (most of them also attending additional evening classes) and an equal number for evening courses and classes only. In addition, more than 1,200 have enrolled at four associated evening institutes which are under the direct charge of the principal of the Technical College.

During the interim eight years pending completiou of the College buildings, the courses of study provided have been steadily augmented in range and progressively developed in level. Provision is now made for Higher National Certificate and corporate membership students in mechanical, electrical and production engineering, in bvilding and in applied physics. Ordinary National Certificate courses are also provided in chemistry and commerce, and the former are developing towards Higher levels and the associateship of the Royal Institute of Chemistry. There is a wide range of crafts courses-many of them based on requirements for the full technological certificates of the City and Guilds of London Institute.

Courses for apprentices and journeymen in the printing industry have now been introduced and are meeting an important local need.

The Art Department, hitherto handicapped by lack of facilities, is now developing, and its policy is greatly strengthened by the interest of the University School of Fine Art.

The Commerce Department, offering courses leading to the intermediate and final examinations of many professional bodies, is also responsible for courses in modern foreign languages, retail distribution, grocery and further general education.

Domestic and women's trade subjects include various needlecrafts, catering, cookery, nursery nurses' work and pre-nursing. 'Much of this work is based on examinations; but provision is also madeat both the College and its associated institutes-for the housewife.

All departments also provide many short courses, including a number of postgraduate or refresher type which are arranged from time to time in consultation with industry, trade, commerce and various professional institutions.

The newly completed premises comprise a main block of four stories of total floor area about 100,000 sq. ft., and a workshops block of some $25,000 \mathrm{sq}$. ft. In order to provide, at this stage, the accommodation essential for the present known demands, emphasis has been placed on workshops, laboratories and drawing offices rather than on classrooms. There is no central hall or gymnasium ; but a refectory, staff and sturlents' common rooms, departmental libraries and staff studies have been included. There is also one large main lecture theatre. A master plan has been prepared by the architects for future develop. ment. The internal arrangements of the new buildings have been carefully planned in respect of both shortterm and probable long-term requirements; they have been made as flexible as possible so that changes in the use of rooms and services can be made as simply and economically as possible. Invisible ceiling panel heating is provided, allowing uninterrupted wall space. Filament lighting is used generally, except for drawing offices and certain rooms in the Art and Printing Department, where fluorescent lighting is preferred.

In general planning, regard has been paid not only to the specific needs of each department but also to encourage the closest possible liaison between them, in the strong belief that all contribute their special elements within the total pattern of life to-day and also that each has much of lasting cultural value to share.

A plinth is provided in the main College forecourt for the display of pieces of sculpture, to be replaced every three years on the basis of a special competition arranged in co-operation with the University.

\section{NATIONAL INSTITUTE FOR RESEARCH IN DAIRYING}

T

HE annual report of the National Institute for Research in Dairying is a tribute to the remarkable variety of work which is being done to improve dairy products. Established in 1912 at the University of Reading, the Institute now has eight research departments. Three of these-the Departments of Dairy Husbandry, Feeding and Metabolism, and Physiology-deal, for the most part, with the problems, both immediate and fundamental, associated with the technique and scientific background of milk production. Included in the scope of these three Departments are questions of dairy farm management, the growing of crops suitable for feeding dairy cattle, the nutrition of dairy stock, and control of reproduction and lactation in cattle.

The other five departments-Bacteriology, Chemistry, Physics, Engineering and Nutrition-deal with the application of science both to farm production and to the more strictly industrial side of practical dairying. Problems, both ad hoc and basic, associated with distribution and manufacture of milk, and with the quality of milk products, are dealt with in these Departments, and they are inevitably concerned from time to time with investigations directly affecting the consumer of milk and of other dairy products.

Besides these eight Departments, there are Sections concerned with isotopes, statistics and psychology, as well as an experimental dairy.

Many investigations were begun or continued during the year. Further work on the rate of milk and milk-fat secretion, for example, has confirmed that the former decreases with increasing interval since the last milking more rapidly than the latter; the positive correlation between the milking-rate of an individual animal and the total lactation yield has been confirmed. It was also shown that the greatest number of new udder infections occurs in the first month of lactation, and in quarters which have not previously been infected the new infectionrate is found to be approximately 3 per cent in the 